\title{
基于CO2FIX模型的华北落叶松人工林碳循环过程
}

\author{
贾彦龙 ${ }^{1,2}$ 李倩茹 ${ }^{1,2}$ 许中旗 $^{1^{*}}$ 桑卫国 $^{3}$ \\ ${ }^{1}$ 河北农业大学林学院, 河北保定 $071000 ;{ }^{2}$ 中国科学院地理科学与资源研究所, 北京 $100101 ;{ }^{3}$ 中国科学院植物研究所植被与环境变化国家重点实验 \\ 室, 北京 100093
}

摘 要 为了探明华北落叶松(Larix gmelinii var. principis-rupprechtii)人工林的碳循环过程, 该研究以河北围场地区的华北落 叶松人工林为例, 基于CO2FIX模型, 以在当地的实际调查数据、文献数据作为输入数据, 从生物量、土壤和木质林产品碳库 3 个方面探讨了华北落叶松人工林的碳循环过程和碳汇能力。结果表明: 华北落叶松人工林土壤碳库最大, 生物量碳库次之, 林产品碳库最小, 但是林产品碳库随时间呈逐渐增加的趋势; 在一个轮伐期内(50年), 每公顷华北落叶松人工林约固定了 250 $\mathrm{t}$ 碳, 其中约 $70 \%$ 通过调落物和采伐剩余物的方式进入土壤碳库, 约 $30 \%$ 进入木质林产品碳库; 华北落叶松人工林在生长的大 部分时间是一个碳的吸收汇, 而在森林采伐时成为暂时的排放源, 从长时间尺度上看, 每公顷华北落叶松人工林每年大约固 定0.3 t左右的碳。该研究结果表明了木质林产品碳库在人工林碳循环中的重要作用, 这将有助于更加全面地认识人工林的碳 循环过程和碳汇能力。

关键词 华北落叶松人工林; 碳循环; 模型模拟; 碳汇能力

引用格式: 贾彦龙, 李倩茹, 许中旗, 桑卫国 (2016). 基于CO2FIX模型的华北落叶松人工林碳循环过程. 植物生态学报, 40, 405-415. doi: 10.17521/cjpe.2015.0208

\section{Carbon cycle of larch plantation based on CO2FIX model}

\section{JIA Yan-Long ${ }^{1,2}$, LI Qian-Ru ${ }^{1,2}$, XU Zhong-Qi ${ }^{1 *}$, and SANG Wei-Guo ${ }^{3}$}

${ }^{1}$ College of Forestry, Agriculture University of Hebei, Baoding, Hebei 071000, China; ${ }^{2}$ Institute of Geographic Sciences and Natural Resources Research, Beijing 100101, China; and ${ }^{3}$ State Key Laboratory of Vegetation and Environmental Change, Institute of Botany, Chinese Academy of Sciences, Beijing100093, China

\section{Abstract}

Aims Plantations play important roles in modifying regional carbon budget and maintaining regional carbon balance. In this study, we assessed larch plantation (Larix gmelinii var. principis-rupprechtii) carbon dynamics in Weichang County from a perspective of the forest biomass-soil-wood-products chain. Our objectives were to elucidate the carbon sink capacity of larch plantation and the influences of biomass, soil and wood product pools on carbon balance.

Methods CO2FIX model was used to evaluate the carbon storage and flow of larch plantation over a time span of 120 years. Input data for model were derived from practical investigations and published papers. We validated the simulated results and found that this model was suitable in the region and the simulated results were reliable.

Important findings (1) Soil was the largest carbon pool for larch plantation and the wood product pool had the smallest carbon storage. Meanwhile, carbon storage in wood products gradually increased with time. (2) In a rotation of 50 years from secondary poplar-birch forest to larch plantation, $250 \mathrm{t} \mathrm{C} \cdot \mathrm{hm}^{-2}$ was sequestrated by the larch plantation. $70 \%$ of the carbon was transferred into soil in the form of litter and logging slash and the other $30 \%$ was transferred into wood products. (3) Larch plantation was a carbon sink during most of its growing period and turned to temporary carbon source when it was harvested. Larch plantation could sequestrate about $0.3 \mathrm{t}$ $\mathrm{C} \cdot \mathrm{hm}^{-2} \cdot \mathrm{a}^{-1}$ in the long term. Our results indicated the importance of wood product carbon pool in carbon dynamics of plantation, which facilitated our understanding in the carbon dynamics and capacity of plantation.

Key words larch plantation; carbon cycle; CO2FIX model; carbon sequestration

Citation: Jia YL, Li QR, Xu ZQ, Sang WG (2016). Carbon cycle of larch plantation based on CO2FIX model. Chinese Journal of Plant Ecology, 40, 405-415. doi: 10.17521/cjpe.2015.0208

收稿日期Received: 2015-06-08 接受日期Accepted: 2016-01-18

* 通信作者Author for correspondence (E-mail: xzq7110@163.com) 
森林生态系统是陆地生态系统最大的碳库, 在 全球碳平衡中发挥着重要作用(Dixon et al., 1994)。 在我国, 森林生态系统同样是最大的碳库, 具有最 大的碳汇能力(方精云等, 2007), 人工林在其中具有 重要的作用(Fang et al., 2001)。数据显示, 我国是世 界上人工林面积最大且增加最快的国家。根据第八 次全国森林资源清查(2009-2013年)的结果, 我国人 工林面积达到6 933万 $\mathrm{hm}^{2}$ (国家林业局, 2014)。种植 人工林不仅可以保护和改善生态环境, 而且可以为 人类的生产生活提供大量的木材。所以, 造林对碳 吸存的影响不仅体现在生物量碳库和土壤碳库中, 还体现在木材制成的丰富的木质林产品中(Masera et al., 2003)。因此, 将植被的生物量碳、土壤碳和 林产品碳作为连续的整体, 系统全面地评价人工林 的碳循环过程和碳汇能力具有重要意义。

源于产品生命周期的思想, 国外学者较早开展 了包括木质林产品在内的整个森林系统生命周期碳 收支的研究。例如, Nabuurs和Schelhaas (2002)利用 CO2FIX模型模拟了欧洲典型森林生态系统的碳收 支, 该模型包括了生物量、土壤和林产品碳库; Brack和Richards (2002)利用CAMFor模型模拟计算 了澳大利亚不同轮伐期包括林产品碳库在内的整个 森林生态系统的碳流通。在国内, 我国学者对森林 生态系统碳储量和碳循环的研究已有很多, 方精云 等(2006)基于生物量、土壤碳库调查和生态系统呼 吸实际观测, 构建了北京东灵山3种森林生态系统 的碳循环模式; 张雷明等(2006)基于浴度相关技术 观测了中国东部4种典型森林的碳收支情况; 白彦 锋等(2009)利用储量变化法、生产法、大气流动法 估算了1961-2004年我国木质林产品碳储量的变化。 然而, 将森林生态系统碳库(生物量碳库与土壤碳 库)和林产品碳库结合在一起研究森林碳循环过程 的研究在我国仍非常缺之。

模型模拟是研究森林碳循环的重要方法, 黄忠 良(2000)基于Century模型对不同管理措施下马尾松 (Pinus massoniana) 林的土壤碳储量、植被生产力进 行了模拟研究; 顾峰雪等(2010)基于改进后的 CEVSA2模型模拟分析了亚热带红壤丘陵区人工林 生态系统碳储量和碳通量的变化特征; 刘瑞刚等 (2009)使用LPJ-GUESS植被动态模型对北京山区3 种森林生态系统未来的碳平衡进行了模拟分析。然 而, 这些碳循环模型只关注森林生态系统内部(植
被、调落物和土壤)的碳循环过程，对于森林砍伐后 的林产品碳流通过程却很少涉及。而CO2FIX模型的 主要特点就是在考虑森林生物量碳库、土壤碳库的 基础上增加了林产品模块, 这使得系统研究人工林 从种植到采伐利用过程的碳流通成为可能, 因此, 该模型自开发后在全球范围内得到了广泛的应用 (Nabuurs \& Schelhaas, 2002; Kaul et al., 2010; Negash \& Kanninen, 2015)。

华北落叶松 (Larix gmelinii var. principisrupprechtii)具有速生、丰产、优质、抗性强等特点, 是河北北部地区的主要造林树种。以往的研究对该 地区华北落叶松人工林的生物量碳库、土壤碳库进 行了报道(杜红梅等, 2009; 耿丽君等, 2010), 而对 于林产品碳库还未见报道。本研究以该地区的华北 落叶松人工林为研究对象, 应用CO2FIX模型模拟 了该人工林生物量、土壤和林产品碳库整个的碳循 环过程, 试图回答以下两个问题：1)华北落叶松人 工林是 $\mathrm{CO}_{2}$ 的吸收汇还是排放源? 2)生物量碳、土 壤碳和林产品碳在华北落叶松人工林碳循环及碳汇 能力中的作用如何?

\section{1 材料和方法}

\section{1 研究区概况}

研究地点位于河北省围场县木兰围场国有林场 管理局孟㴒林场, 处于冀北山地与内蒙古高原的过 渡地带。地理位置为 $41.58^{\circ}-42.67^{\circ} \mathrm{N}, 116.53^{\circ}$ $118.23^{\circ} \mathrm{E}$, 海拔700-2 $000 \mathrm{~m}$ 。该地区属半湿润半干 旱过渡地带大陆性季风型山地气候, 年平均气温3.3 ${ }^{\circ} \mathrm{C}$, 年降水量 $445 \mathrm{~mm}$, 雨热同季, 降水多集中在 7-9月。森林土壤多为棕色森林土, 并覆有 $10 \mathrm{~cm}$ 厚 腐殖质层。

该地区森林资源丰富, 森林类型复杂多样, 天 然林以杨桦林、云杉(Picea asperata)林、油松(Pinus tabuliformis)林和蒙栋(Quercus mongolica)林为主。自 20世纪60年代以来, 华北落叶松以其速生、丰产、优 质、抗性强等特性成为该地区人工造林的主要树种。 华北落叶松林内主要伴生有白桦 (Betula platyphylla)、山杨(Populus davidiana)等乔木, 林下灌木主 要有胡枝子(Lespedeza bicolor)、榛(Corylus heterophylla)、毛榛(Corylus mandshurica), 草本植物主要有 乌苏里荎草(Carex ussuriensis)、龙牙草(Agrimonia pilosa)、林地早熟禾(Poa nemoralis)等。华北落叶松 
人工林受到人类管理活动的影响，当地林场制定了 华北落叶松人工林的经营管理方案并严格执行, 如 抚育间伐的时间、频率、强度及主伐时间等。

\section{2 研究方法}

\subsection{1 模型简介}

CO2FIX V 2.0是一个林分尺度(公顷级)的森林 生态系统碳计量模型, 能够在年尺度上模拟各碳库 的储量和通量。该模型包括生物量模块、土壤模块 和木质林产品模块, 3 个模块是有机结合的一个连续 整体。生物量碳库中的碳一方面通过调落物、森林 采伐剩余物的形式进入土壤碳库, 为土壤碳库的循 环提供物质基础; 另一方面, 生物量碳通过采伐的 方式移出生态系统, 进入木质林产品碳库继续进行 碳储存和碳流通的过程。该模型在应用上呈现出以 下特点: 适用于天然林和人工林的生态系统; 适用 于同龄或异龄的纯林或混交林; 适用于多层次的农 林复合生态系统。因此, 该模型自开发后在全球范围 内得到了广泛的应用, 在不同气候带、不同类型的森 林生态系统碳循环模拟上均有较好的结果(Nabuurs \& Schelhaas, 2002; Kaul et al., 2010; Negash \& Kanninen, 2015)。下面就其3个模块进行详细介绍。

生物量模块考虑了树木生长、分配、周转、死 亡、竞争、管理措施(采伐)等对森林碳储量的影响。 其中, 树木树干的生长是影响森林生物量的一个最 主要的因素, 该模型给出了两种描述树干生长量的 模式。一种是Chapman-Richards模式:

$$
a=A /\left(1+e^{-(\beta+k t) / v}\right)
$$

式中, $a$ 为 $t$ 时刻林分的生物量, $A$ 为林分能够达到的 最大的生物量, $\beta 、 k$ 和 $v$ 为估计的参数。

这种模式适用于林龄确定的林分。而实际上, 考虑到数据的可获取性, 在模型计算的过程中是以 方程(1)的倒数(即林分的年增长量(current annual increment, $C A I)$ )来计算林分的生物量, $C A I$ 的数据可 从传统的收获表获得, 这也是本研究所采用的方法, 通过这一方法可以得到林分每年生物量的碳储量和 增加量。

另一种是适用于林龄不易确定的热带森林, 该 模式的表达式为:

$$
B_{\mathrm{i}}=A\left(B_{\max }-B\right) B^{k}
$$

式中, $B_{\mathrm{i}}$ 为林分生物量增量, $B$ 为实际生物量, $B_{\max }$ 为 可达到的最大生物量, $A 、 k$ 为估计的参数。

在确定了树干的年生长量之后, 根据一定的分
配系数就可以计算其他器官(枝、叶、根)的年生长 量。树木的各器官每年有一定的比例会枯死作为调 落物的形式进入土壤, 这成为土壤模块的碳输入源 之一, 另一个输入源是森林采伐后留在林地的采伐 剩余物。此外, 在混交林的情形下, 该模型还考虑了 竞争对树木生长的影响。

该模型的土壤模块是镶嵌的YASSO模型。该模 块模拟计算土壤的碳储量主要由三部分决定: 土壤 的初始碳密度, 每年的碳输入量(即调落物量), 每 年的碳输出量(即土壤碳的分解释放量)。土壤初始 碳密度可有两种方法获得, 一是根据测定数据直接 输入, 输入数据包括现存的非木质调落物碳量、细 木质调落物碳量、粗木质调落物碳量、可溶性组分 碳量、纤维素碳量、木质素碳量、腐殖质碳量。第 二种方法是输入造林前每年的调落物量, 由模型自 动计算出初始碳密度。土壤模块中每年的碳输入量 与生物量模块相耦合, 该数据由生物量模块中树木 每年的调落物量、细根周转量、死亡树木、采伐剩 余物的量提供。土壤的分解速率由土壤凋落物的质 量和数量及当地的环境条件决定。凋落物的质量和 数量可从前面的计算得到, 需要的环境数据主要是 年平均气温、生长季降水量和土壤水分蒸发蒸腾损 失总量。

林产品模块的原理是追踪生物量碳从森林采伐 到分解的全过程。该模块考虑了森林砍伐后形成的 各种产品及各产品的比例, 将各种产品按照使用的 寿命分为长期产品、中期产品和短期产品, 并假定 各产品按照其使用寿命以指数形式废弃。在产品被 废弃后, 考虑其多少比例分别被用于再利用、燃烧、 丢弃于垃圾场或埋于地下。最后这些产品中的碳通 过分解或燃烧的方式回到大气。该模块提供了默认 参数和实际调查参数两种方式来计算林产品的碳储 量和通量, 为了使得模拟结果更接近实际情况, 本 研究通过实际调查提供了华北落叶松林产品的相关 参数, 如形成了哪些产品、各产品的比例、回收再 利用情况等。

\subsection{2 模型模拟及数据来源}

本研究以该地区的华北落叶松人工林为研究对 象, 用CO2FIX模型模拟了其碳循环过程, 模拟时间 为120年, 假定在每个轮伐期后继续用同样的方法 种植、管理华北落叶松。模型模拟所需的主要输入 数据见表1, 其来源介绍如下。 
表1 模拟华北落叶松人工林碳 动态的主要参数

Table 1 Main parameters in carbon dynamic simulation of larch (Larix gmelinii var. principis-rupprechtii) plantation

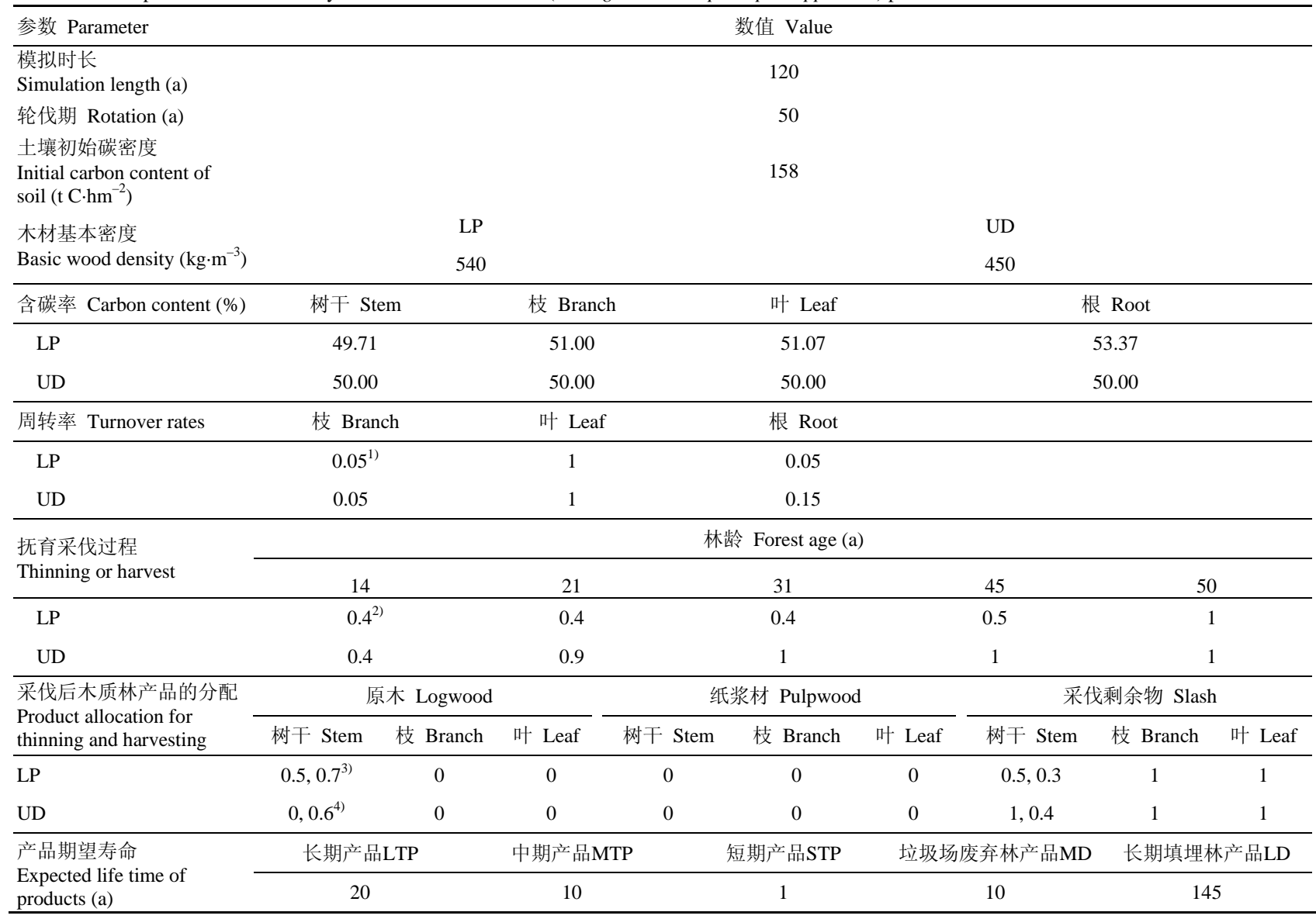

1), 此处的 0.05 表示每年枝生物量的 $5 \%$ 枯损调落。2), 此处的 0.4 表示采伐时现存林分蓄积量的 $40 \%$ 被采伐。3), 此处的 0.5 表示前三次采伐树木生物量 的 $50 \%$ 生产为原木, 0.7 表示后两次采伐树木生物量的 $70 \%$ 生产为原木, 原木、纸浆材、采伐剩余物之和为总采伐量(即三个数值之和为 1$)$ 。 4 ), 此处的 0 和0.6分别表示林下植物在前三次和后两次采伐中树木生物量生产为原木的比例。LP, 华北落叶松人工林; UD, 林下植物。

1), the value of 0.05 represent that $5 \%$ of branch biomass is decayed each year. 2 ), the value of 0.4 represent that $40 \%$ of stand volume is thinned. 3 ), the value of 0.5 represent that $50 \%$ of tree biomass thinned is produced into logwood in the first three thinning, and 0.7 represent that $70 \%$ of tree biomass thinned is produced into logwood in the last two thinning; the value of logwood, pulpwood, and slash sum to 1. 4), the value of 0 and 0.6 represent the percentage of tree biomass is produced into logwood in the first three thinning and the last two thinning, respectively. LP, Larch plantation; UD, understory; LTP, long-term products; MTP, medium-term products; STP, short-term products; MD, mill site dump; LD, landfill.

生物量模块需要的主要输入数据包括树木的生 长表(收获表)、生物量在树木各器官的分配比例、 各器官的含碳量、各器官的周转率、树木的死亡率 及抚育采伐的时间、强度等。在本研究中, 华北落 叶松树干生长量(表2)、含碳量数据分别来自于六新 刚和崔相慧(2001)、马钦彦等(2002)的研究结果。华 北落叶松人工林林下植被(主要是山杨、白桦)的生 长量是基于对该地区这些树种树干解析数据的推算 (贾彦龙等, 2012)。华北落叶松和林下树种的木材基 本密度、周转率等数据来自于模型的使用手册。华 北落叶松人工林的抚育采伐时间和采伐强度来自于 当地林场现行的经营方案, 轮伐期为 50 年, 期间还 有4次间伐过程(分别在14年、21年、31年、45年), 其 采伐强度见表1。
表2 华北落叶松人工林及林下植被树干生长量

Table 2 Stem growth rate of larch and undergrowth vegetation

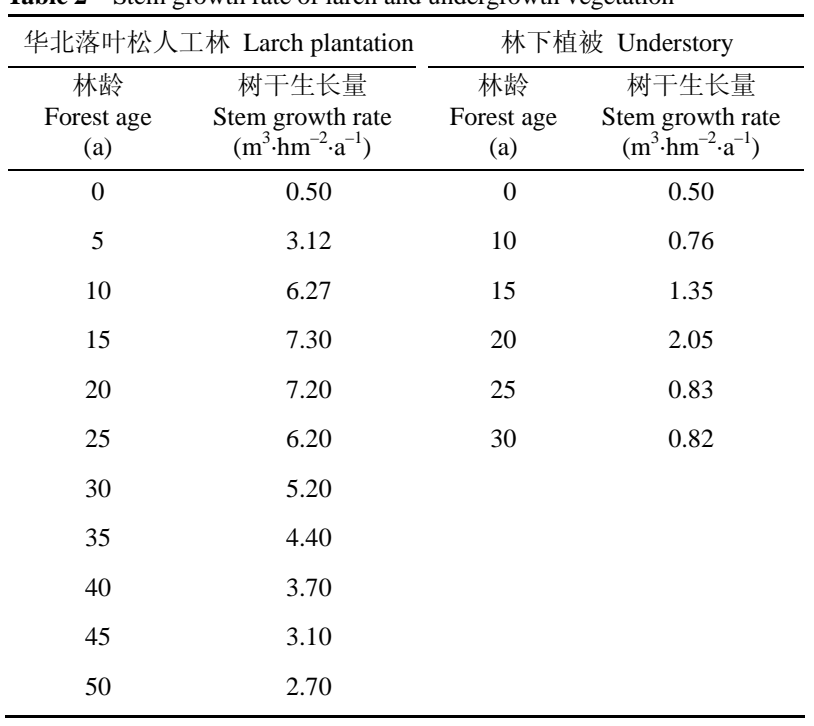


土壤模块需要的主要输入数据是土壤初始密度 (即造林前土壤碳密度)、当地的气候数据(平均气温 和生长季降水量)和土壤水分蒸发蒸腾损失总量。由 于本研究没有详细调查土壤初始密度, 因此土壤初 始密度采用模型的第二种方法得到, 即由造林前每 年的调落物量作为输入数据计算得到。该地区造林 前的植被类型为杨桦天然次生林, 因此, 依据对该 地区杨华天然次生林生物量的调查结果(贾彦龙等, 2012), 结合各器官的周转率, 最终计算得到造林前 每年的调落物量。该地区的年平均气温、生长季降 水量数据从网站(www.worldclimate.com)得到, 土 壤水分蒸发蒸腾损失总量由月平均温度计算得到。 该网站的气象数据来源于全球历史气象网络 (Global Historical Climatology Network)的数据产品, 该数据产品是基于全球 6000 个气温观测站、7500 个降水观测站的长期历史数据整合而成, 可提供全 球月尺度的平均气温、平均降水量数据。该数据具 有较高的可靠性, 因此也被CO2FIX模型推荐作为 该模型的气象数据输入源。为了验证该数据产品在 研究地的适用性, 我们从中国气象科学数据共享网 下载了研究地附近的气象观测站数据, 结果显示两 者具有很好的一致性(图1), 表明全球历史气象网络 数据产品在本研究地区具有很好的适用性。

林产品模块主要的输入数据是木材的使用方 式、各种林产品的分配比例和使用寿命、产品废弃 后的利用方式及比例。在本研究中, 我们通过问卷 调查的方式对当地的杆子厂、木材加工厂进行了调 查, 明确了华北落叶松木材在当地的使用方式和产
品流向。调查发现, 矿柱、枕木、普通建材(门、窗 等)、托盘和包装材料是当地华北落叶松木材的主要 使用方式, 并确定了各产品的使用比例。产品的平 均使用寿命数据来自于白彦锋(2010)对中国木质林 产品使用寿命的调查结果。

模型的输出结果是各个碳库(干、枝、叶、根、 土壤、短期产品、中期产品、长期产品等)每年的碳 储量、每年的输入量和每年的输出量。根据这些结 果可以计算出各碳库的储量值和碳库之间的通量 值, 如净初级生产力 $(N P P)$ 、生态系统净生产力 $(N E P)$ 、土壤呼吸等。

\subsection{3 模型验证}

为了验证该模型在该地区的模拟效果, 我们在 2008-2010年调查了该地区9、12、13、30、32年华 北落叶松人工林的生物碳储量, 具体的采样和测定 方法见文献(贾彦龙等, 2012)。由图2可见, 华北落叶 松人工林碳储量的模拟值与实测值具有较好的吻合 性, 同时, 成对样本 $t$ 检验的结果显示模拟值与实测 值之间无显著差异 $(p=0.225)$ 。这表明CO2FIX模型 在河北围场地区是适用的, 对华北落叶松人工林碳 动态的模拟结果有较高的可靠性。此外, 通过将造 林前每年的调落物量作为输入数据, 本研究计算的 华北落叶松人工林土壤的初始碳密度为 $158.05 \mathrm{t}$ $\mathrm{C} \cdot \mathrm{hm}^{-2}$, 这与当地杨桦次生林土壤碳密度的实际调 查数据161.5 t C $\cdot \mathrm{hm}^{-2}$ 非常接近(张兴锐等, 2010)。在 当地, 一般是砍伐杨桦次生林后种植华北落叶松, 华北落叶松人工林的土壤初始碳密度即相当于杨桦 次生林的土壤碳密度, 所以本研究对于土壤碳储量
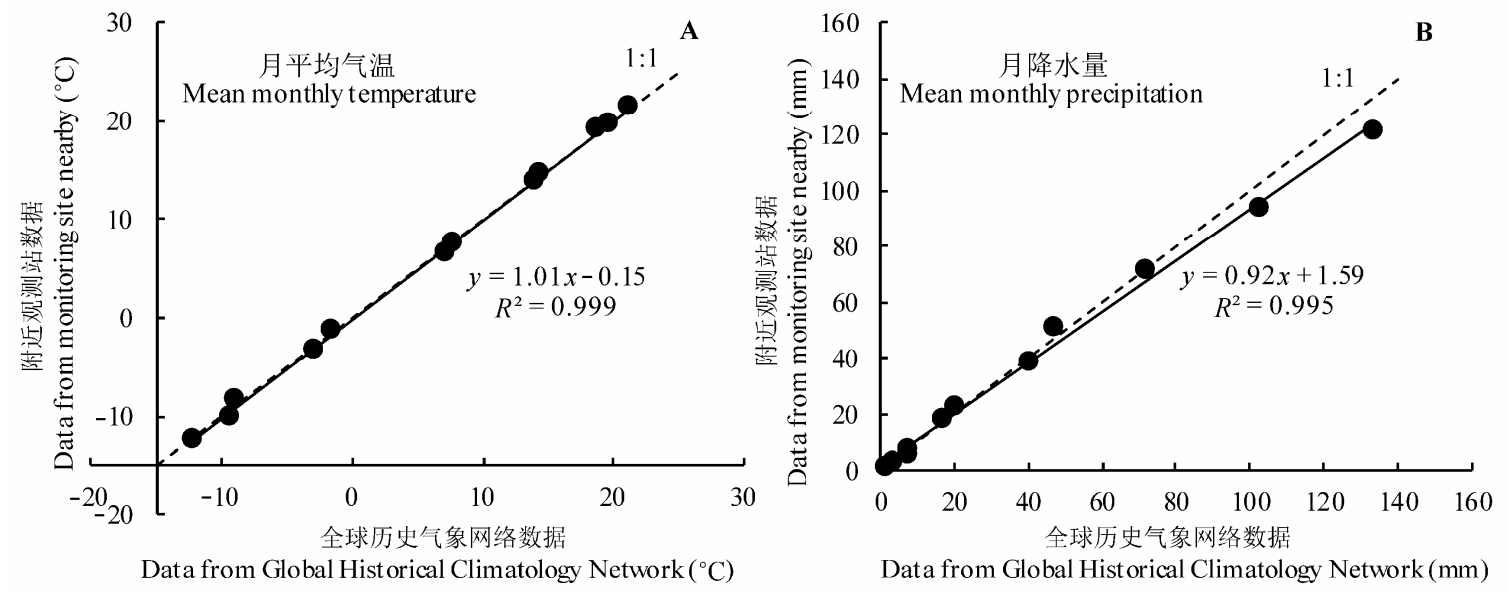

图1 全球历史气象网络数据与附近气象观测站月平均气温(A)和月降水量 $(\mathbf{B})$ 的比较。

Fig. 1 Comparisons between data from Global Historical Climatology Network and data from monitoring site nearby for mean monthly temperature (A) and mean monthly precipitation (B). 


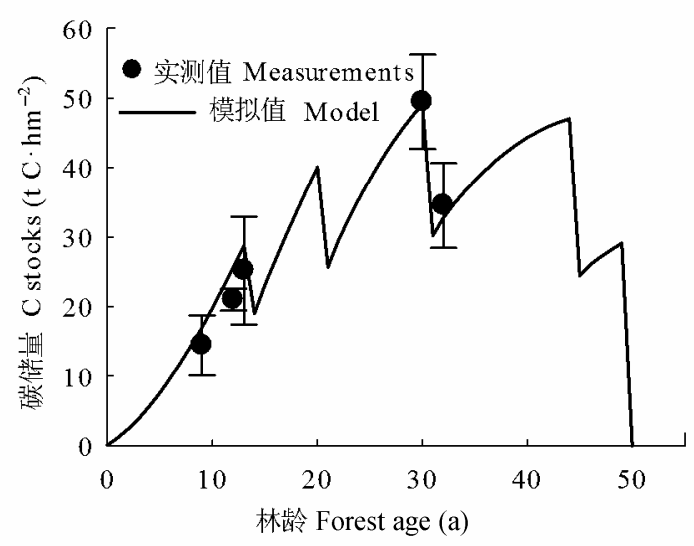

图2 华北落叶松人工林生物碳储量模拟值与实测值的比较 (平均值土标准偏差)。

Fig. 2 Comparison between simulated and measured values of biomass carbon storage in larch plantation (mean $\pm S D$ ).

的模拟也具有较高的可信度。真实的追踪林产品碳 流通的全过程是难以做到的, 利用调查数据与模型 相结合是目前较好的评估林产品碳流通的方法, 其 结果的可靠性主要依赖于调查结果是否全面、客观, 本研究以后将加强林产品流通方面的调查, 使其结 果更加可靠。

\section{2 结果}

\section{1 华北落叶松人工林的碳储量变化}

华北落叶松人工林生物量、土壤、林产品碳库 及总碳储量的动态变化如图3所示。从图中可以看 出, 华北落叶松人工林生物量碳和总碳储量具有相 似的变化趋势，以轮伐期为周期呈现周期性变化, 变化范围分别为 $0-50 \mathrm{t} \mathrm{C} \cdot \mathrm{hm}^{-2}$ 和150-200 t C.hm ${ }^{-2}$, 疏伐、主伐后碳储量明显下降，且采伐对生物量碳 的影响更为剧烈; 土壤碳储量在每个轮伐期内均呈 现先降低后波浪式上升的趋势, 每次疏伐均会短暂 增加土壤碳储量, 而主伐后土壤碳储量会大幅下降, 碳储量的变化范围大致在130-160 t C. $\mathrm{hm}^{-2}$; 与其他 碳库不同, 林产品碳储量随时间呈现逐渐增加的趋 势, 每次采伐后林产品碳储量短暂快速增加, 随后 又快速降低，但总体仍呈现增加的趋势。

\section{2 华北落叶松人工林净初级生产力的变化}

$N P P$ 反映了植物实际固定 $\mathrm{CO}_{2}$ 的能力。在本研 究中, 华北落叶松人工林的 $N P P$ 是由林木各器官(树 干、枝、叶、根)碳的年增量加和得到, 其动态变化 如图4所示。华北落叶松人工林的 NPP随轮伐期呈周 期性变化, 变化范围为1.5-7.5 t C. $\mathrm{hm}^{-2} \cdot \mathrm{a}^{-1}$ 。在每个

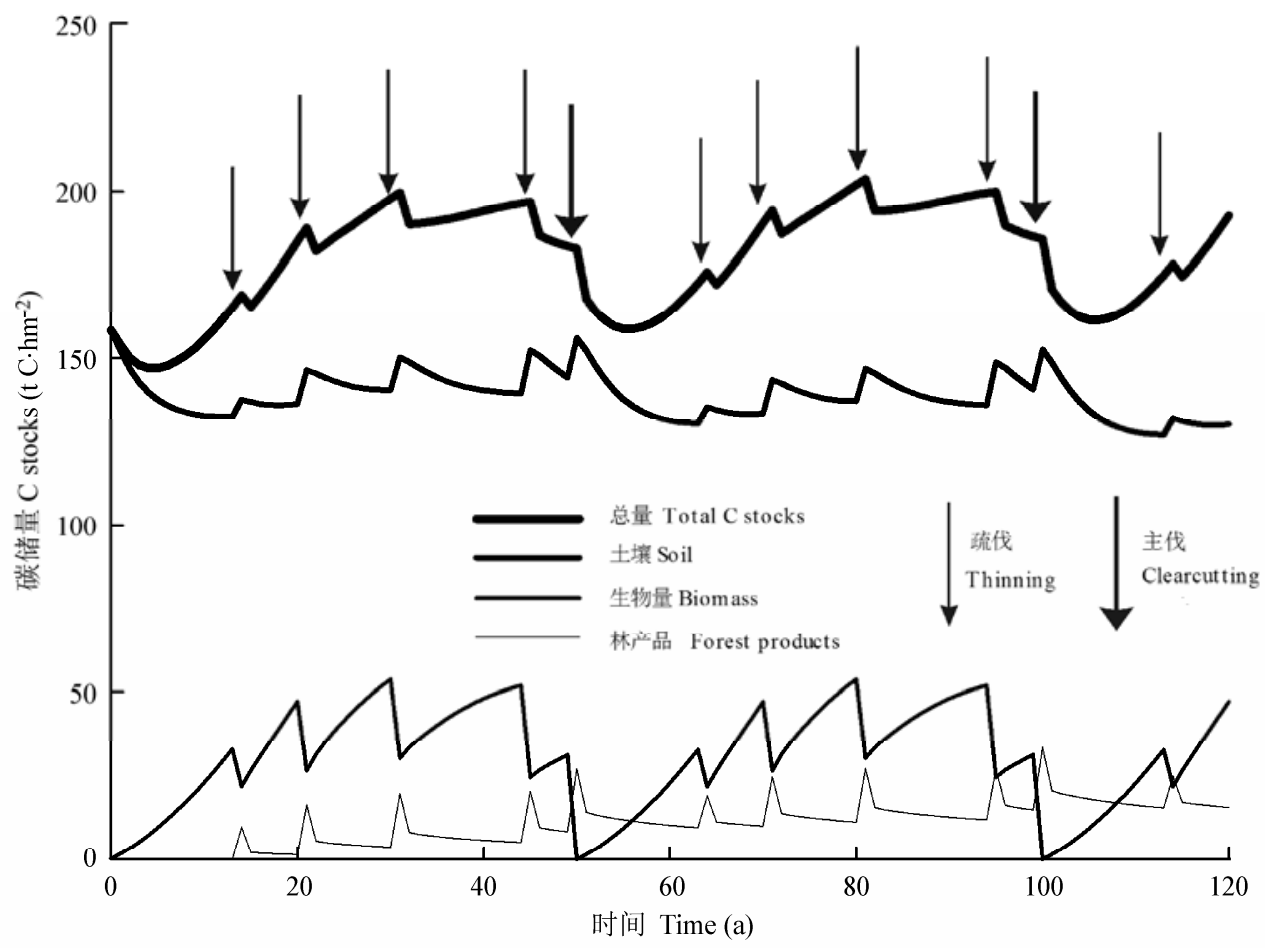

图3 华北落叶松人工林碳储量动态变化。

Fig. 3 The dynamics of carbon storage in larch plantation. 


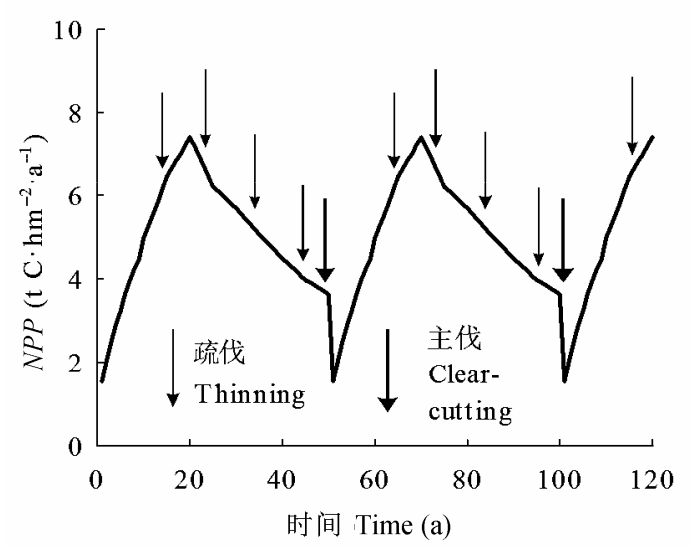

图4 华北落叶松人工林净初级生产力 $(N P P)$ 的变化。

Fig. 4 The dynamics of net primary productivity $(N P P)$ in larch plantation.

轮伐期内, NPP先较快增加, 在20年左右达到峰值, 然后逐渐下降，大部分时间内 $N P P$ 保持 $4 \mathrm{t}$ $\mathrm{C} \cdot \mathrm{hm}^{-2} \cdot \mathrm{a}^{-1}$ 以上的高碳吸存能力。我们发现, 除了主 伐外，其他的几次抚育间伐对华北落叶松人工林的 $N P P$ 没有明显影响, 这说明生态系统的 NPP主要是 由植物自身生长特性和环境容量决定, 而抚育间伐 则主要影响树木单株的生产力。

\section{3 华北落叶松人工林的碳源汇分析}

华北落叶松人工林净碳平衡的变化如图5所示。 当净碳平衡为正值时, 表示华北落叶松人工林为碳 汇, 即生物量碳库、土壤碳库和林产品碳库每年总 的碳输入大于碳输出, 反之则为碳源。从图 5 可以看 出, 在大部分时间里，华北落叶松人工林是一个明 显的碳汇，尤其是在林龄为10-30年这一华北落叶 松快速生长期，而在林分幼龄期和成熟期表现为碳 源。同时, 森林采伐是影响人工林碳源汇功能的重 要因素, 森林采伐后造成大量碳的快速释放使得华 北落叶松人工林成为暂时的碳源。

由于华北落叶松人工林碳平衡的强度和方向随 时间呈现剧烈的波动(图5), 不利于我们在长时间尺 度上认识其到底是碳源还是碳汇及其碳源汇的强 度, 因此, 本研究采用年平均净碳平衡(advancing mean of the net annual sink)(Nabuurs \& Schelhaas, 2002)这一指标来反映长时间尺度上森林的碳源汇 功能。第 $n$ 年的年平均净碳平衡由 $0-n$ 年的碳平衡之 和除以 $n$ 得到。从图 5 可以看出, 在第一次造林的华 北落叶松成林后, 逐渐成为一个稳定的碳汇, 年平 均净碳平衡在 $0.3 \mathrm{t} \mathrm{C} \cdot \mathrm{hm}^{-2}$ 左右, 即每公顷的华北落

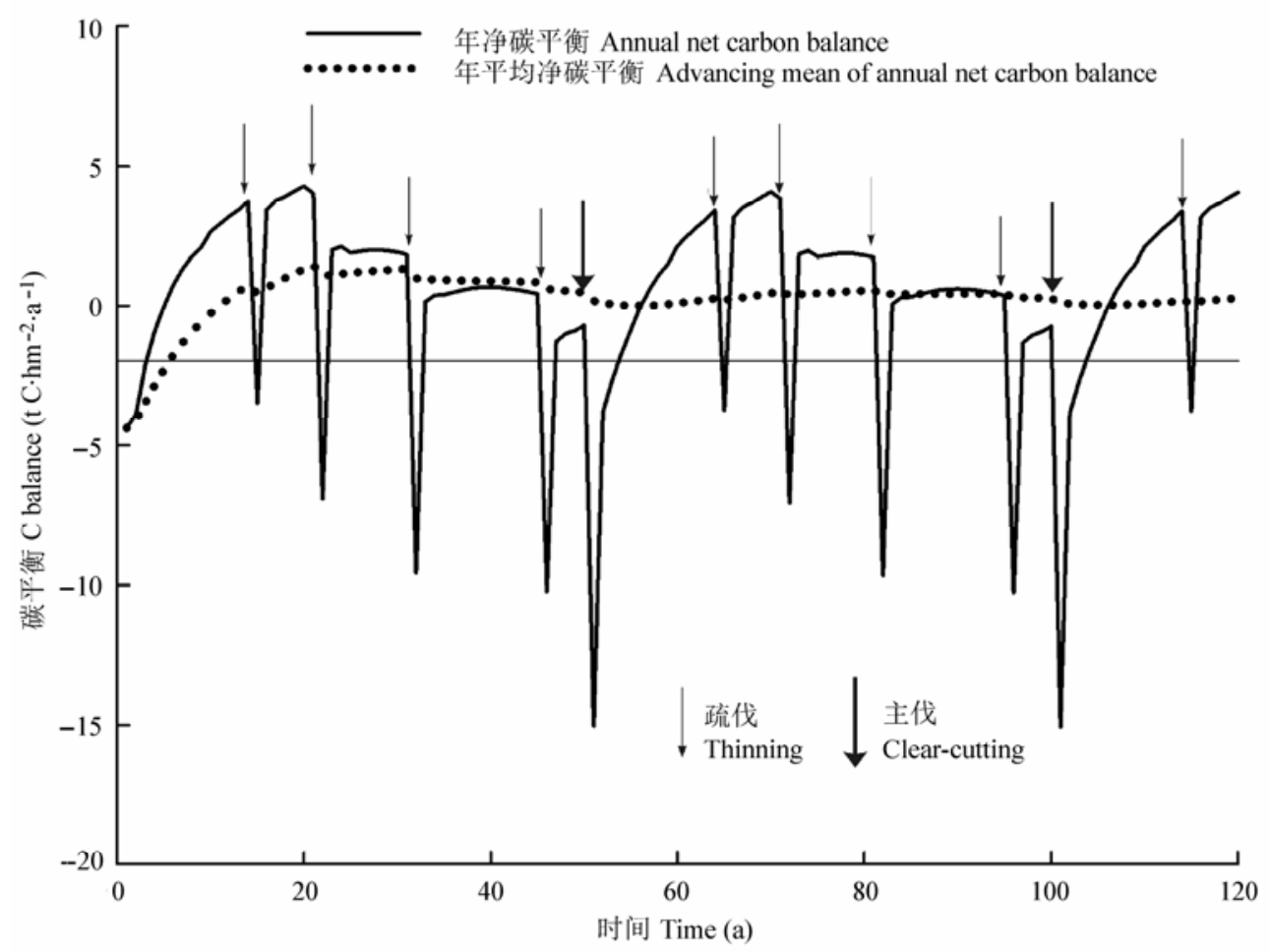

图5 华北落叶松人工林净碳平衡的变化。

Fig. 5 The dynamics of net carbon balance in larch plantation. 
叶松人工林每年大约固定 $0.3 \mathrm{t}$ 的碳。

\section{4 华北落叶松人工林的碳流通}

华北落叶松人工林一个轮伐期内(50 a)的碳流 通情况如图6所示。在一个轮伐期内, 每公顷华北落 叶松人工林净截存约 $250 \mathrm{t}$ 碳, 其中约 $70 \%$ 通过凋落 物和采伐剩余物的方式进入土壤碳库, 约 $30 \%$ 进入 木质林产品碳库。在轮伐期结束后, 华北落叶松人 工林被全部采伐, 植物碳库的储量几乎为 0 ; 土壤 碳库由于持续的分解作用, 其碳储量有略微降低的 趋势; 林产品碳库则成为最大的碳库, 虽然其也通 过燃烧和分解的方式不断释放碳, 在轮伐期结束后 依然有26.78 t的碳储存在林产品中。

\section{3 讨论}

本研究基于CO2FIX模型将生物量碳库、土壤碳 库和木质林产品碳库作为整体, 系统研究了华北落 叶松人工林的碳循环过程及其碳源汇能力。研究发 现, 从碳源汇的动态变化来看, 华北落叶松人工林 在大部分时间是一个明显的碳汇，其碳汇强度最高 约为 $4.5 \mathrm{t} \mathrm{C} \cdot \mathrm{hm}^{-2} \cdot \mathrm{a}^{-1}$ (图5), 而在每次森林采伐后会
形成一个暂时的碳源; 从长时间尺度来看, 华北落 叶松人工林也逐渐成为一个稳定的碳汇，每公顷的 华北落叶松人工林每年大约固定 $0.3 \mathrm{t}$ 左右的碳。因 此, 整体上来说, 在河北围场地区种植华北落叶松 人工林有助于对大气 $\mathrm{CO}_{2}$ 的固定，能够发挥森林碳 汇的作用。同时, 本研究结果也表明生物量碳库、 土壤碳库和木质林产品碳库在华北落叶松人工林碳 循环过程和碳源汇功能方面具有不同的作用。

树木通过光合作用将大气中的 $\mathrm{CO}_{2}$ 吸收、固定 在生物量中, 可以说树木既是碳的截存单位, 又是 碳的储存单位。从本研究碳储量的结果(图3)来看, 虽然生物量碳库不是总碳库的最大组分, 但是其主 导了总碳储量的变化趋势, 说明生物量碳是总碳储 量变化中最活跃的组分。这是由于华北落叶松具有 快速生长的特性，即使采伐造成了生物量碳的快速 下降, 其也能通过快速的生长继续固定大量的碳, 并且固定的碳量超过生态系统呼吸的强度, 从而在 华北落叶松人工林生长的大部分时期保持碳汇的作 用(图5)。树木除了吸收和固定碳, 还通过调落物和 采伐剩余物的方式将碳转移到土壤和木质林产品碳

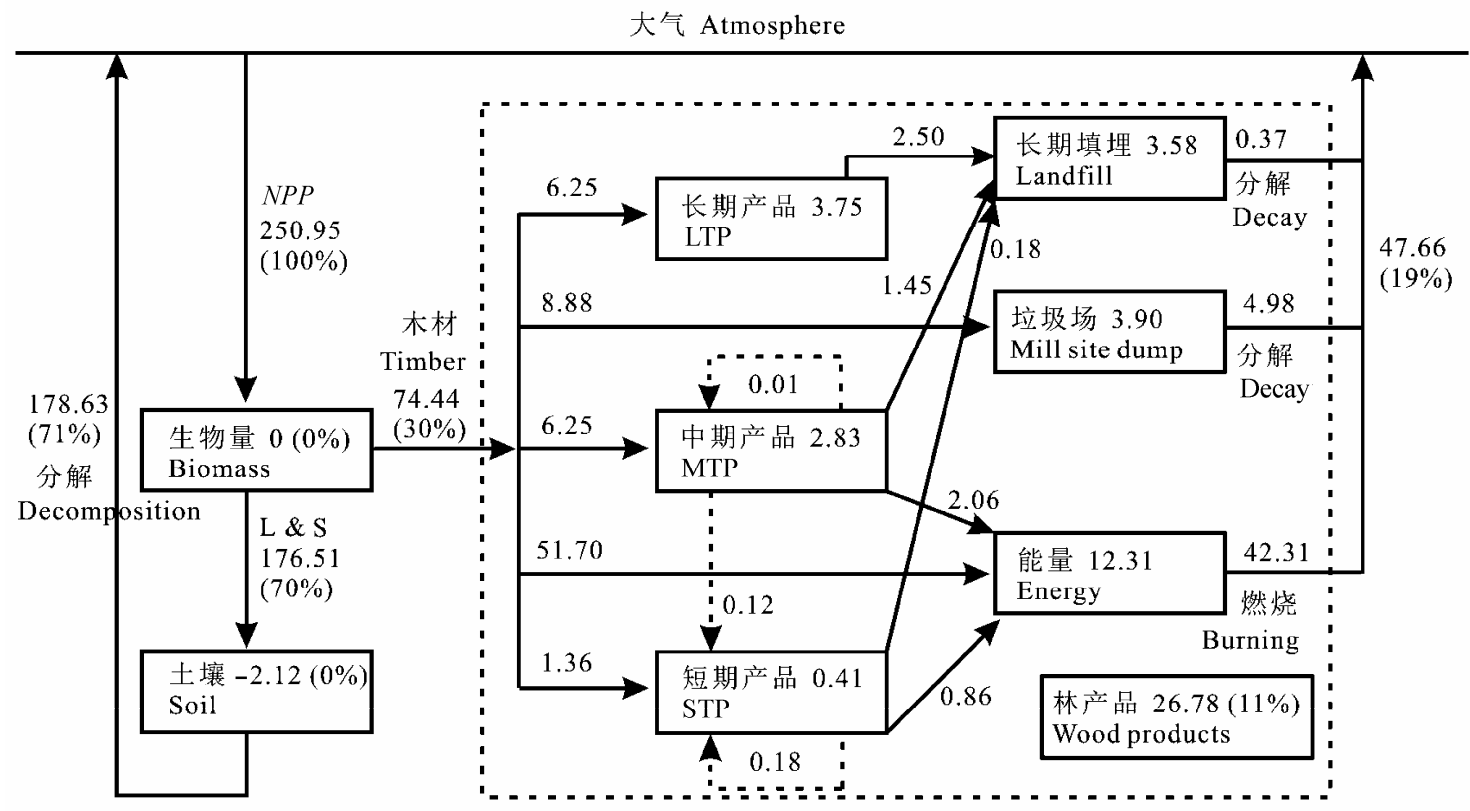

图6 一个轮伐期内华北落叶松人工林的碳流通 $\left(\mathrm{t} \mathrm{C} \cdot \mathrm{hm}^{-2}\right)$ 。 NPP 为净初级生产力, $\mathrm{L} \& \mathrm{~S}$ 为调落物和采伐剩余物。数字表示一 个轮伐期(50 a)内进入某一碳库总的碳通量或轮伐期后碳库最终的碳储量, 括号内的百分数表示该碳通量或碳储量与总净初 级生产力之比。

Fig. 6 Carbon flow of larch plantation in a 50-year rotation $\left(\mathrm{t} \mathrm{C} \cdot \mathrm{hm}^{-2}\right)$. NPP is net primary productivity; $\mathrm{L} \& \mathrm{~S}$ represents litter and logging slash; LTP, MTP, STP represent long term products, medium term products and short term products, respectively. Numbers in arrows represent carbon fluxes to certain carbon pool, and numbers in boxes represent carbon storage in certain carbon pool. The percentages in parentheses represent ratios of carbon fluxes or carbon storages to total net primary productivity. 
库中。

土壤碳库是森林生态系统最大的碳库。在本研 究中, 土壤碳库亦是华北落叶松人工林最大的碳库 (图3), 但是从土壤碳库在森林碳源汇功能中的作用 来看, 栽植华北落叶松一个轮伐期后, 土壤碳库却 成为一个轻微的碳源(图6)。这与造林前的土地利用 历史有关。在河北围场地区, 华北落叶松造林前为 杨华天然次生林, 其主要组成树种是山杨、白华、 纸皮桦(Betula papyrifera)等落叶阔叶树种。研究表 明, 相比华北落叶松等针叶树种, 阔叶树种具有更 高的周转率, 尤其是在细根的周转上(张小全和吴 可红, 2001)。因此, 杨桦天然次生林每年有更多的 调落物和细根进入土壤, 使得土壤保持了高的碳储 量, 而栽植华北落叶松后, 其凋落物量的减少可能 造成了土壤碳储量的下降。与王彦梅等(2010)和姜 发艳等(2009)对辽东山区和川西亚高山天然次生林 和原始林转化为人工林后土壤碳变化的研究相似。

在本研究中, 华北落叶松人工林木质林产品碳 库是最小的碳库, 但是其碳储量呈现逐渐增加的趋 势(图3)。这是因为在该地区, 华北落叶松的木材除 了一部分作为薪材燃烧了之外, 还有较大部分成为 矿柱、枕木、门窗等中长期木质产品。因此, 随着 采伐量的增加, 储存在木质产品中的碳也逐渐增加, 即使在森林被主伐后(生物量碳库储量几乎为 0 ), 仍 有26.78 t碳储存在木质产品中(图6)。传统上一般认 为人工林在被砍伐后其碳储存的功能也会消失, 本 研究的结果将有助于全面认识人工林的碳汇作用, 尤其在我国拥有如此大面积人工林的情况下, 这一 问题应得到更多的重视。

总结来看, 华北落叶松人工林整个的碳循环过 程是落叶松生长特性、环境条件和人类活动共同影 响的结果。在华北落叶松人工林幼龄期, 由于植株 矮小、地表裸露, 使得地表温度升高进而导致土壤 呼吸增加, 再加之调落物很少, 这种输入少、输出多 的情形使得土壤碳库在这一时期成为碳源。随着林 分的快速增长, 森林逐渐郁闭, 调落物的输入也增 加, 前面的情况逐渐好转, 森林碳汇的能力也逐渐 体现出来。长到一定阶段后, 树木之间对于环境资 源的竞争逐渐明显, 抚育间伐这一人类活动开始介 入进来。间伐虽然使得林分密度降低, 但给存活的 树木更大的资源空间, 促进了单株树木的快速生长, 所以间伐没有对生态系统的NPP形成大的影响, 落
叶松林依然保持了较快的生长。间伐产出的木材一 部分作为薪材燃烧, 一部分形成林产品继续发挥碳 储存的作用。在林分发展后期, 森林的生产力逐渐 降低, 森林被主伐后进入下一轮循环。

本研究的结果从森林碳汇的角度对当地林业生 产的指导意义在于：1)华北落叶松人工林幼龄期的 土壤碳库是一个碳源, 林业生产部门应加强对这一 时期土壤的保护, 通过一定的措施减少土壤碳汇的 流失；2)合理的抚育间伐不会降低森林生态系统的 生产力, 而且林产品是一个更持久的碳库, 所以以 后的抚育间伐应该和林产品生产联系起来, 使得间 伐产出的木材能够更有利于生产长期的林产品。

本研究利用CO2FIX模型试图从生物量、土壤和 木质林产品碳库3个方面较全面地认识华北落叶松 人工林的碳循环过程和碳汇能力, 但是仍然还存在 一些不足需要我们以后更深入探讨。1)华北落叶松 人工林的培育管理措施主要包括苗木培育、造林、 抚育间伐和主伐, 每一个过程都需要大量人力和物 力的投入, 消耗大量能量的同时释放了大量的 $\mathrm{CO}_{2}$ 到空气中, 这一部分碳排放也应该计入人工林碳汇 能力的核算中。2) CO2FIX模型中没有评估火灾、 病虫害等干扰对森林生长的影响, 这可能会造成对 森林碳汇能力的部分高估。我们建议以后应加强这 两个方面的研究, 以进一步更加全面地认识和评估 人工林的碳汇能力。

基金项目中国科学院战略性先导科技专项 (XDA05050203-02-01)和河北省科技厅科技支撑项 目 (10236728)。

\section{参考文献}

Bai YF (2010). Carbon Stocks of Harvested Wood Products in China. PhD dissertation, Chinese Academy of Forestry, Beijing. (in Chinese with English abstract) [白彦锋 (2010). 中国木质林产品碳储量. 博士学位论文, 中国 林业科学研究院, 北京.]

Bai YF, Jiang CQ, Zhang SG (2009). Carbon stock and potential of emission reduction of harvested wood products in China. Acta Ecologica Sinica, 29, 399-405. (in Chinese with English abstract) [白彦锋, 姜春前, 张守攻 (2009). 中国木质林产品碳储量及其减排潜力. 生态学报, 29, 399-405.]

Brack CL, Richards GP (2002). Carbon accounting model for forests in Australia. Environmental Pollution, 116, S187S194.

Dixon RK, Solomon AM, Brown S, Houghton RA, Trexier 
MC, Wisniewski J (1994). Carbon pools and flux of global forest ecosystems. Science, 263, 185-190.

Du HM, Wang C, Gao HZ (2009). Carbon-sink function of artificial Larix principis-rupprechtii plantation. Chinese Journal of Eco-Agriculture, 17, 756-759. (in Chinese with English abstract) [杜红梅, 王超, 高红真 (2009). 华北 落叶松人工林碳汇功能的研究. 中国生态农业学报, 17, 756-759.]

Fang JY, Chen AP, Peng CH, Zhao SQ, Ci LJ (2001). Changes in forest biomass carbon storage in China between 1949 and 1998. Science, 292, 2320-2322.

Fang JY, Guo ZD, Piao SL, Chen AP (2007). Terrestrial vegetation carbon sinks in China from 1981 to 2000. Science in China Series D: Earth Sciences, 37, 804-812. (in Chinese) [方精云, 郭兆迪, 朴世龙, 陈安平 (2007). 1981-2000 年中国陆地植被碳汇的估算. 中国科学 $\mathrm{D}$ 辑: 地球科学, 37, 804-812.]

Fang JY, Liu GH, Zhu B, Wang XK, Liu SH (2006). Carbon budgets of three temperate forest ecosystems in Dongling Mt., Beijing, China. Science in China Series D: Earth Sciences, 36, 533-543. (in Chinese) [方精云, 刘国华, 朱 彪, 王效科, 刘绍辉 (2006). 北京东灵山三种温带森林 生态系统的碳循环. 中国科学 $\mathrm{D}$ 辑: 地球科学, 36, 533-543.]

Geng LJ, Xu ZQ, Zhang XR, Xi CX, Lu JP, Sun XM, Huang XR (2010). Biological carbon storage in Larix principisrupprechtii plantations in north region of Yanshan Mountain. Journal of Northeast Forestry University, 38(6), 43-45, 52. (in Chinese with English abstract) [耿丽君, 许 中旗, 张兴锐, 席常新, 卢金平, 孙晓梅, 黄选瑞 (2010). 燕山北部山地华北落叶松人工林生物碳咜量. 东北林业大学学报, 38(6), 43-45, 52.]

Gu FX, Tao B, Wen XF, Yu GR, Li KR (2010). Modeling long-term changes in carbon fluxes and storage in a subtropical coniferous plantation based on CEVSA2 model. Acta Ecologica Sinica, 30, 6598-6605. (in Chinese with English abstract) [顾峰雪, 陶波, 温学发, 于贵瑞, 李克 让 (2010). 基于CEVSA2模型的亚热带人工针叶林长 期碳通量及碳储量模拟. 生态学报, 30, 6598-6605.]

Huang ZL (2000). Application of a century model to management effects in the productivity of forests in Dinghushan. Acta Phytoecologica Sinica, 24, 175-179. (in Chinese with English abstract) [黄忠良 (2000). 运用Century模型模拟 管理对鼎湖山森林生产力的影响. 植物生态学报, 24 , 175-179.]

Jia YL, Xu ZQ, Ji XL, Xu XH, Huang XR (2012). Biological carbon storage of plantation and natural secondary forest in north region of Yanshan Mountain. Journal of Natural Resources, 27, 1241-1251. (in Chinese with English abstract) [贾彦龙, 许中旗, 纪晓林, 徐学华, 黄选瑞 (2012). 燕山北部山地人工林和天然次生林的生物碳咜

\section{量. 自然资源学报, 27, 1241-1251.]}

Jiang FY, Sun H, Lin B, Liu Q (2009). Dynamic changes of top soil organic carbon in subalpine spruce plantation at different succession stages in western Sichuan Province. Chinese Journal of Applied Ecology, 20, 2581-2587. (in Chinese with English abstract) [姜发艳, 孙辉, 林波, 刘 庆 (2009). 川西亚高山云杉人工林恢复过程中表层土 壤碳动态变化. 应用生态学报, 20, 2581-2587.]

Kang XG, Cui XH (2001). The tree growth table of larch plantation. The Journal of Hebei Forestry Science and Technology, (3), 21-23. (in Chinese) [元新刚, 崔相慧 (2001). 华北落叶松人工林生长过程表的编制. 河北林业科技, (3), 21-23.]

Kaul M, Mohren GMJ, Dadhwal VK (2010). Carbon storage and sequestration potential of selected tree species in India. Mitigation and Adaptation Strategies for Global Change, 15, 489-510.

Liu RG, Li N, Su HX, Sang WG (2009). Simulation and analysis on future carbon balance of three deciduous forests in Beijing mountain area, warm temperate zone of China. Chinese Journal of Plant Ecology, 33, 516-534. (in Chinese with English abstract) [刘瑞刚, 李娜, 苏宏新, 桑卫 国 (2009). 北京山区3种暖温带森林生态系统未来碳平 衡的模拟与分析. 植物生态学报, 33, 516-534.]

Ma QY, Chen XL, Wang J, Lan C, Kang FF, Cao WQ, Ma ZB, Li WY (2002). Carbon content rate in constructive species of main forest types in Northern China. Journal of Beijing Forestry University, 24(5/6), 96-100. (in Chinese with English abstract) [马钦彦, 陈遐林, 王娟, 萄琛, 康峰峰, 曹文强, 马志波, 李文宇 (2002). 华北主要森林类型建 群种的含碳率分析. 北京林业大学学报, 24(5/6), 96100.]

Masera OR, Garza-Caligaris JF, Kanninen M, Karjalainen T, Liski J, Nabuurs GJ, Pussinen A, de Jong BHJ, Mohren GMJ (2003). Modeling carbon sequestration in afforestation, agroforestry and forest management projects: The CO2FIX V.2 approach. Ecological Modelling, 164, 177199.

Nabuurs GJ, Schelhaas MJ (2002). Carbon profiles of typical forest types across Europe assessed with CO2FIX. Ecological Indicators, 213-223.

Negash M, Kanninen M (2015). Modeling biomass and soil carbon sequestration of indigenous agroforestry systems using CO2FIX approach. Agriculture, Ecosystems and Environment, 203, 147-155.

State Forestry Administration (2014). China Forests Resources Report-The Eighth National Forest Inventory. China Forestry Publishing House, Beijing. [国家林业局 (2014). 中国森林资源报告一一第八次全国森林资源清查. 中 国林业出版社, 北京.]

Wang YM, Wang P, Yu LZ (2010). Effects of conversion from

www.plant-ecology.com 
natural secondary forests to plantations on soil organic carbon in mountainous region of eastern Liaoning Province. Journal of Northeast Forestry University, 38(12), 54-57. (in Chinese with English abstract) [王彦梅, 王朋, 于立忠 (2010). 辽东山区天然次生林转化为人工林对 土壤有机碳的影响. 东北林业大学学报, 38(12), 54-57.]

Zhang LM, Yu GR, Sun XM, Wen XF, Ren CY, Song X, Liu YF, Guan DX, Yan JH, Zhang YP (2006). Seasonal characteristics of carbon budget in forest ecosystems along the North-South Transect of East China. Science in China Series D: Earth Sciences, 36, 45-59. (in Chinese) [张雷明, 于贵瑞, 孙晓敏, 温学发, 任传友, 宋霞, 刘允芬, 关德 新, 问俊华, 张一平 (2006). 中国东部森林样带典型生 态系统碳收支的季节变化. 中国科学 $\mathrm{D}$ 辑: 地球科学, 36, 45-59.]
Zhang XQ, Wu KH (2001). Fine-root production and turnover for forest ecosystems. Scientia Silvae Sinicae, 37(3), 126-138. (in Chinese with English abstract) [张小全, 吴 可红 (2001). 森林细根生产和周转研究. 林业科学, 37(3), 126-138.]

Zhang XR, Xu ZQ, Ji XL, Jia YL, Huang XR, Lu JP, Zhang JS (2010). Soil organic carbon storage and its distribution of the typical communities in the north region of Yanshan Mountain. Journal of Soil and Water Conservation, 24(1), 186-190, 196. (in Chinese with English abstract) [张兴锐, 许中旗, 纪晓林, 贾彦龙, 黄选瑞, 卢金平, 张劲松 (2010). 燕山北部山地典型植物群落土壤有机碳咜量及 其分布特征. 水土保持学报, 24(1), 186-190, 196.]

责任编委: 王根绪 责任编辑: 李 敏

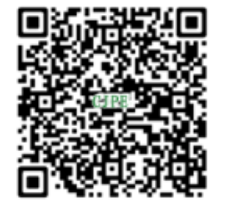

植物生态学报官网 唯一投稿网址

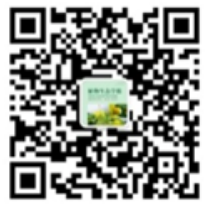

微信订阅号

期刊及学科 相关信息发布

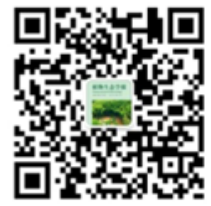

微信服务号

稿件状态查询 全文检索测览 